\title{
Addressing Aggression in the Residential Setting for Juveniles with Mild Intellectual Disability through Training in Non-Violent Resistance
}

\author{
K. M. Visser ${ }^{1,2} \cdot$ L. M. C. Jansen ${ }^{1} \cdot$ A. Popma ${ }^{1,4} \cdot$ R. R. J. M. Vermeiren ${ }^{3} \cdot$ M. C. Kasius ${ }^{2}$
}

Accepted: 12 September 2020 / Published online: 30 September 2020

(c) The Author(s) 2020

\begin{abstract}
Background Levels of aggression are high in residential settings for juveniles with Mild Intellectual Disability (MID). As a result, treatment is less effective, aggression causes injury, traumatic experiences and longer inhabitation for juveniles. Additionally, inpatient aggression has been linked to burnout and stress among group workers, which has negative consequences such as less job satisfaction or poorer work performance

Objective Therefore, it is crucial to diminish aggressive incidents in these settings and to find a way for staff how to respond to aggression properly.

Methods As there is no intervention method which tackles all of the referred problems efficiently, a new method Non-violent Resistance for MID was introduced into three residential settings for juveniles with MID, in a quasi-experimental stepped wedge design. Reports of aggressive incidents were assessed seven times before, during and after the training in NVR-MID on group level. Multilevel analyses were carried out in order to assess the development of the aggressive incidents over time.

Results Aggressive incidents decreased significantly in time during and after training in NVR-MID, this decrease is seen in all three institutions. Thus, regardless of resident's age, gender or IQ, NVR-MID seemed successful in diminishing aggressive incidents. Furthermore, a significant interaction effect was found between institution and time, indicating that regardless if incidents of aggression were relatively high at baseline, decrease in incidents was similar to institutions where incidents were relatively low on baseline.

Conclusions Implementing NVR-MID into residential settings for juveniles with MID and comorbid behavioral problems might help to decrease aggressive incidents.
\end{abstract}

Keywords Non-violent resistance $\cdot$ Residential care $\cdot$ Mild intellectual disabilities · Aggression

K. M. Visser

km.visser@amsterdamumc.nl

Extended author information available on the last page of the article 


\section{Introduction}

Although the average population of residential youth care settings varies in prevalence of comorbid psychopathology (such as anxiety, aggression or other psychopathology), a substantial part of the admitted juveniles have problems with their anger management (Livingston et al. 2010). Aggression directed at self or others seems to be the major reason for referral to inpatient mental health services (Cowley et al. 2005; Gardner and Moffatt 1990). About half of the juveniles in a residential institution have a (sub-) clinical level of aggressive behavior (Wielemaker 2009). Additionally, in residential settings for juveniles with a mild intellectual disability are substantial levels of aggression and intimidating behavior on a daily basis (Crocker et al. 2006; Crotty et al. 2014; Emerson et al. 2001). Mild intellectual disability (MID) is defined as having below average intelligence quotient (IQ) between 50 and 70 (AmericanPsychiatricAssociation 2000). Additionally, when experiencing limitations in their social adaptability juveniles with an IQ between 70 and 85 are also included in the definition MID (Zoon 2013). These limitations in social adaptability are found to be one of the explanatory mechanisms for externalizing and aggressive behavior (Van Nieuwenhuijzen et al. 2009). Specifically, limitations in their social information processing, as it has been explained by the Social Information Processing Model (Crick and Dodge 1994), might be a reason for problematic behavior (Van Nieuwenhuijzen et al. 2009). The researchers argue that social problem solving difficulties and response generation (e.g. generating a response in a new situation Van Nieuwenhuijzen et al. 2005, 2006)) were found to be an explanatory mechanism for externalizing and aggressive behavior in children with MID (Van Nieuwenhuijzen et al. 2009). The amounts of aggressive incidents reported in these MID-institutions are evidently higher than in institutions for juveniles with average intelligence (Embregts et al. 2009). In these settings, aggressive incidents between the juveniles and between juveniles and the working staff are remarkably high (Zeller et al. 2012). Externalizing behavior in the research literature consist of disruptive, hyperactive and aggressive behaviors (Liu 2004), whereas aggression is defined as "behavior that is intended to harm someone physically or psychologically", (Tillaart et al. 2018). Up to 60\% of juveniles make assaultive threats and attempts against other patients and staff (Pfeffer et al. 1985). In the past, the main reaction to aggression was setting rules and limits, constraints and sanctions all too often resulting in physical and spatial containment (James 2011). However, instead of diminishing the aggression, aggressive incidents peaked, while a restrictive climate in the residential institutions arose. A negative, restrictive or closed group climate is defined by an (extreme) asymmetrical balance in power between group workers and juveniles, high levels of repression and lack of mutual respect (Van der Helm et al. 2009). Some elements of a restrictive climate, such as dependency (Van der Helm et al. 2009) and/or competition (Helm and Stams 2012) have been found to be associated with aggressive incidents (Ros et al. 2013). A restrictive climate subsequently hampers the development of children, since a negative influence on the treatment outcome has been demonstrated (Lipsey 2009; Parhar et al. 2008). Furthermore, aggressive incidents in residential youth care settings have negative consequences for the juveniles as well as for the group workers. Use of restrictive methods can cause injury, traumatic experiences and a longer inhabitation for the aggressive juvenile (Sukhodolsky et al. 2005). Additionally, inpatient aggression has been linked to burnout and stress among group workers (Edwards and Miltenberger 1991; Hunter and Carmel 1992; Tenneij and Koot 2008). Consequences for group workers who have had to deal with aggression include: more difficulties with continuing work, less job satisfaction, more thoughts about job resignation, poorer work 
performance and more absenteeism (Jackson et al. 2002). Therefore, it is important to prevent aggressive incidents in residential settings and especially for juveniles with MID and find an appropriate way for staff to respond to aggression. However, different studies show that existing (evidence-based) interventions for juveniles with psychiatric problems need to be adjusted to have the same effect for juveniles with psychiatric problems and MID (de Wit et al. 2011; Kazdin 2005; Sanders et al. 2004; Schudrich 2012).

An alternative method to deal with aggressive behavior is adopting a non-restrictive attitude, as is promulgates in Non-violent resistance (NVR). NVR is based on the philosophy and methods that were used by Gandhi and Martin Luther King in their social-political struggle and originates from the method 'Non-violent Resistance: A New Approach to Violent and Self-Destructive Children', which the Israeli psychologist Haim Omer, and others, developed (Omer 2004). Omer's method primarily focuses on changing the behavior of the caretaker instead of that of the juvenile and aims to decrease problematic behavior by restoring the struggling relationship between juvenile and caretaker. NVR is a systematic approach to help caregivers, such as parents, teachers and staff of mental health care facilities, cope with juveniles' problematic behavior. This is done in a non-violent and non-escalating way, for example through "announcements", "sit-ins" and "reparation acts". To illustrate, the latter are interventions in which the juvenile is explicitly given the opportunity to fix caused harm through apologizing or literally restoring damage, such as replacing broken goods (Omer and Lebowitz 2016). NVR was initially developed to support parents of children with behavioral problems. Parents were trained to adequately respond to their child's unwanted behavior and to increase positive parent-child interaction within the family environment (Omer and Lebowitz 2016). In this form, NVR has proven to be effective in reducing juveniles externalizing (Van Holen et al. 2016; Weinblatt and Omer 2008) and internalizing symptoms (Van Holen et al. 2016), escalations between child and parent (Weinblatt and Omer, 2008), and helplessness and stress on the side of the parents (Van Holen et al. 2016; Weinblatt and Omer 2008). NVR could possibly also contribute to impressive treatment results in residential youth care. An adaptation for the application in a residential setting was developed in order to ensure a better fit (Goddard et al. 2009). Since group workers, in the same way as parents, can find themselves in a struggling relationship with the institutionalized juveniles (Natta et al. 1990; Patterson and Forgatch 1985). The first results of the adaptation for the residential setting appear to be promising and show that staff members are positive about the training in NVR and report feeling more relaxed (van Gink et al. 2018a, b). The researchers expected aggressive incidents to decrease after implementing NVR, also based on theoretical models that view the emergence of aggressive behavior as a transactional process (Fontaine and Dodge 2009; Sameroff 2009), where the interaction between the patient's behavior and the environment potentially leads to violence and aggression. When embedding this theory into NVR, it could be expected that in case the environment would be more friendly towards the patients (due to the de-escalating attitude of group workers), the aggression of admitted juveniles would decrease. However, a recent study on the relationship of NVR and aggressive incidents in the residential setting shows that number of incidents do not change after implementing NVR (van Gink et al. 2018a, b). However, the researchers argue that numbers might not be representative of the actual aggressive incidents due to major transformations of the institutions themselves regardless of the NVR method (van Gink et al. 2018a, b). Thus, further research on that matter is very much needed required.

Considering the high prevalence of MID in residential settings generally, the necessity to meet the need of this target group and the promising results of NVR in different settings, the residential NVR method was additionally adjusted for the work with juveniles with 
Table 1 Training of staff in NVR-MID and measurement-points of aggressive incidents at the three residential sites in a quasi-experimental stepped wedge research design

\begin{tabular}{|c|c|c|c|c|c|c|c|c|c|}
\hline Sites & Aug '16 & Nov'16 & Feb ' 17 & May '17 & Aug '17 & Nov'17 & Feb'18 & May '18 & Aug '18 \\
\hline 1 & TO & T1 & T2 & T3 & T4 & T5 & T6 & & \\
\hline 2 & & TO & T1 & T2 & T3 & T4 & T5 & T6 & \\
\hline 3 & & & TO & T1 & $\mathrm{T} 2$ & T3 & T4 & 15 & $T 6$ \\
\hline
\end{tabular}

\begin{tabular}{|l|l|}
\hline & Pre-Training Measurements \\
\hline & During-Training Measurements \\
\hline & Post-Training Measurements \\
\hline & No Measurement \\
\hline
\end{tabular}

MID (Haspels et al. 2017). To give some examples, interventions as the announcement were adjusted, wherein the message for the juvenile was made more visual, compared to the regular NVR version. Furthermore, the adaptation for MID implies that group workers use clear and concise language when addressing the juveniles. Subsequently, the NVR adaptation for MID, abbreviated with NVR-MID, has been implemented in three different residential settings in the Netherlands recently. This study evaluates whether the method of NVR-MID is successful in decreasing the number of aggressive incidents reported in the residential settings for juveniles with MID. The hypothesis is that training of staff in NVRMID would lead to a decrease in aggressive incidents over time.

\section{Method}

\section{Design}

The data were part of a larger longitudinal effect study on NVR-MID. The study was approved by the Medical Ethics Committee of the VU medical Centre of Amsterdam (2015.344). Data collection started in August 2016 and ran until September 2018. As random allocation to different conditions was not desirable, a quasi-experimental design was used. As the NVR-MID training for staff was introduced on group level in different stages, a stepped-wedge design was used (Brown and Lilford 2006; Campbell and Cook 1979). This design knows several advantages: (1) It is a good choice when implementation in different clusters would be logistically difficult (Brown and Lilford 2006); (2) it is considered as more ethical if the implementation is thought to do more good than harm, because there is no control group which does not get the intervention (Brown and Lilford 2006); (3) the stepped wedge design provides the opportunity to measure possible effects of time of the intervention and to investigate the effects of underlying temporal changes (Brown and Lilford 2006).

In this case there were three phases: (1) 3-0 months before NVR-MID training, (2) 3-9 months during NVR-MID training and (3) 3-6 months after NVR-MID training. Each phase was introduced at the sites at a different time-point, so each cluster could function as its own control group, see Table 1 . In this study site 1 forms the first cluster with two units. Site 2 forms the second cluster with four units. And finally, site 3 forms the third cluster with four units. In addition, due to the repetitions of pre- and post-measurements in different time periods, a possible influence of any outside events, such as Christmas or the 
holiday period, are more easily detected and could therefore be accounted for. There were two pre-training measurements (T0, T1), three during-training measurements (T2, T3, T4) and two post-training measurements (T5, T6). The training of staff in the NVR-MID method covered a total of 9 months (T2, T3, T4).

\section{Participants}

A total of 128 juveniles $^{1}$ of the three residential youth care settings for juveniles with MID and behavioral and/or psychological problems participated $(\mathrm{N}=128)$. Informed consent was obtained from all individual participants included in the study. Total mean age and IQ were expected to be different between the three sites. Age at the first measurement point (T0) ranged from 9 to 50 years old (Mean $=16.52, \mathrm{SD}=5.1$ ). IQ ranged from 42 to 103 (Mean $=63.49, \mathrm{SD}=13.3$ ). Information on the participants' IQ score was obtained through the records. In most cases participants had a valid IQ (e.g. measured through one of the commonly used intelligence tests such as the Wechsler Intelligence Scale for Children-III (WISC; (Wechsler 1949)). In these cases that IQ score was used. If participants did not have a valid IQ, institutions were asked to collect new information on IQ. In most cases this was done by the institution. If institutions were not able to collect the data on a short notice, a shortened version of the WISC was done by one of the research assistants. The shortened version of the WISC consists of the two sub-tests Vocabulary and Block Patterns and gives a good and reliable indication of the total IQ (Legerstee et al. 2004). This version was used in 5 cases. 64 clients (50\%) were admitted to a specialized youth care setting aimed at MID and treatment for severe behavioral problems. 39 clients (30, 5\%) had besides their MID also physical impairments, and 25 clients $(19,5 \%)$ were admitted to a unit with MID facilities and comorbid problems, such as ADHD.

\section{Site 1}

Site 1 was located in a rural area of central Netherlands and was intended for clients with mild to moderate IDs. Clients often stayed here for a long period of time or even lived there permanently. Parents were committed and intertwined with the treatment.

\section{Site 2}

Site 2 was located in the southern Netherlands in a more urban environment. This site was aimed for clients aged from 6 to 21 years with MID and other comorbid psychiatric problems, such as autism, ADHD and/or emotional problems. Some of the clients also had physical impairments, such as being in a wheelchair.

\section{Site 3}

Site 3 was located in a northern part of the Netherlands in a rural surrounding and was aimed for clients between 12 and 23 years old, having severe behavioral problems besides their MID. Most clients were placed here because of a decision of the youth

\footnotetext{
${ }^{1}$ The definition of the term juvenile in our study is based on their mental age, rather than their actual age.
} 
Table 2 Number of participants N, gender male/female, mean age and mean IQ and corresponding standard deviations (SD) and the distributions of juveniles per sector per Site

\begin{tabular}{llllllll}
\hline & $N$ & Gender M/F & $\begin{array}{l}\text { Mean Age } \\
(S D)\end{array}$ & IQ $(S D)$ & $\begin{array}{l}\text { Specialized } \\
\text { youth care } \\
\text { and MID }\end{array}$ & $\begin{array}{l}\text { MID plus } \\
\text { physical } \\
\text { impairment }\end{array}$ & $\begin{array}{l}\text { MID and mild } \\
\text { comorbid } \\
\text { psychiatric } \\
\text { problems }\end{array}$ \\
\hline Site 1 & 12 & $6 / 6$ & $24.9(10.42)$ & $49.14(5.14)$ & - & $7(58.3 \%)$ & $5(41.7 \%)$ \\
Site 2 & 52 & $26 / 26$ & $16.15(4.14)$ & $61.52(12.16)$ & - & $32(61.5 \%)$ & $20(38.5 \%)$ \\
Site 3 & 64 & $29 / 35$ & $15.25(1.81)$ & $76.86(7.26)$ & $64(100 \%)$ & - & - \\
Total & 128 & $61 / 67$ & $16.52(5.1)$ & $63.49(13.3)$ & $64(50 \%)$ & $39(30.5 \%)$ & $25(19.5 \%)$ \\
\hline
\end{tabular}

care system or because parents could not handle the situation with their child at home anymore.

For a detailed overview of the 3 sites and the participant characteristics see Table 2.

\section{Procedure}

The residential settings were approached for the research project by researchers of the VUmc. A research assistant explained the aim of the study to the juveniles at the youth meeting in the ward. If the juveniles were above 16 years, they were allowed to give their consent by signing the consent form themselves. For juveniles between 16 and 12 , their parents or legal guardians had to give consent as well and for juveniles under 12 years only parents/legal guardians had to give consent.

Staff was trained in NVR-MID by highly experienced trainers with a standardized manual (Haspels et al. 2017). The training consisted of three full training days (two days at the start of the training and one day at follow-up to complete the training), in which the principles and interventions of NVR-MID were explained theoretically and practiced hands-on. Every 10 weeks there were three additional supervision meetings where an expert in NVR-MID could give feedback on certain situations participants brought back from the work floor. In this way the method was evaluated and discussed with case descriptions and role-playing games based on staff members' daily work. The supervision meetings had two purposes; one was to embed the method in the daily work more easily; the other concerned implementation fidelity by supervisors ensuring that NVR-MID had been implemented in the daily work routine appropriately.

The settings were asked to provide information on aggressive incidents that had taken place during the study period. We received a data file wherein all aggressive incidents (verbal and physical) were reported by group leaders per unit. Besides the number of incidents, we also received a short description of the incident (e.g.: "Boy was asked to leave the room. Even after several attempts he refused to go upstairs. Ultimately he was forced to leave the room, which led to an escalation.”). Two researchers coded the aggressive incidents independently of one another. The coding included reading the data files and identifying whether the incidents had led to an escalation or not. All aggressive incidents that had led to an escalation where included in this study. 
Table 3 Overview of each measurement-point and its corresponding range of three months wherein aggressive incidents were reported

\begin{tabular}{llll}
\hline $\begin{array}{l}\text { Measure- } \\
\text { ment-point }\end{array}$ & Site 1 & Site 2 & Site 3 \\
\hline T0 & Aug.-Sept. '16 & Nov.'16-Jan. '17 & Feb.-Apr. '17 \\
T1 & Nov.'16-Jan. '17 & Feb.-Apr. '17 & May-Jul. '17 \\
T2 & Feb.-Apr. '17 & May-Jul. '17 & Aug.-Oct. '17 \\
T3 & May-Jul. '17 & Aug.-Oct. '17 & Nov.'17-Jan. '18 \\
T4 & Aug.-Oct. '17 & Nov.'17-1 '18 & Feb.-Apr. '18 \\
T5 & Nov.'17-Jan. '18 & Feb.-Apr. '18 & May-Jul. '18 \\
T6 & Feb.-Apr. '18 & Apr.-Jul. '18 & Aug.-Oct. '18 \\
\hline
\end{tabular}

\section{Instruments}

Reports of aggressive incidents per unit were assessed 7 times in total, 2 times before, 3 times during and 2 times after NVR-MID training of staff. Assessment was done via the Dutch incident registration system MIC (Melding Incident Client). Whenever an aggressive incident had taken place, group workers had to report the aggressive incident in a digital system, describing the nature of the incident (verbal, physical) and what had happened precisely. In this study we explored the incidents that had led to an escalation, e.g. physical restrainment or separation of the client. We made this decision because NVR-MID is especially aimed at avoiding escalations. Per unit, the number of aggressive incidents were collected monthly over the entire study period. They were correlated with all admitted juveniles per unit, resulting in the same number of aggressive incidents for all juveniles per unit. Conclusions can be drawn on group level rather than on individual level. Finally, they were averaged and correlated with each three-monthly measuring moment, see Table 3.

\section{Implementation Fidelity}

Fidelity of the implementation of the method NVR-MID was measured with a questionnaire "Reaction to Unacceptable Behavior-Inventory" (short: RUBI-NL) (Visser et al. 2019). The RUBI-NL consists of 17 items, the questionnaire should be administered individually, is suitable for repeated measurements, and is intended for (mental health care) professionals working in a residential setting. While filling out the questionnaire, the respondent is instructed to keep a serious and difficult incident that had happened on the ward during the previous two weeks in mind. For each item, the respondent can indicate on a five-point scale how likely it is that a certain approach would have been used by the respondents' colleagues. A higher score indicates a good implementation level of the method NVR-MID, because it demonstrates that staff is working in a NVR inspired way. This instrument has been developed for this particular purpose by the authors.

\section{Demographic Measures}

Knowledge about age, gender and IQ was acquired through the sites. In order to map the seriousness and nature of the psychological problems among the juveniles, the Brief Problem Monitor [BPM, (Achenbach et al. 2011)] was used, which is the abbreviated version of the Child Behavior Checklist [CBCL, (T. M. Achenbach, 1991)]. The BPM consists of 
Table 4 Means and standard deviations of brief problem monitor (BPM) scores per residential site before, during and after NVR-MID training

\begin{tabular}{llll}
\hline BPM & Pre (T0, T1) & During (T2, T3, T4) & Post (T5, T6) \\
\hline Residential Site & $M(S D)$ & $M(S D)$ & $M(S D)$ \\
Site 1 & $15.7(7.01)$ & $18.8(6.33)$ & $16.6(7.6)$ \\
Site 2 & $15.4(6.7)$ & $14.9(8.8)$ & $12.3(6.5)$ \\
Site 3 & $16.6(6.4)$ & $13.7(7.3)$ & $17.9(6.5)$ \\
\hline
\end{tabular}

19 items of emotional and behavioral problems and is administered by a group leader for each juvenile individually. Examples of items are "argues a lot" or "impulsive or acts without thinking"'. All items can be answered with $0=$ Not true, $1=$ somewhat true or $2=$ Very true. An overview of the average BPM scores before, during and after NVR-MID training per site can be seen in Table 4 .

\section{Analyses}

To analyze and answer the research questions we used SPSS (IBM, SPSS Statistics 21). First, descriptive analyses were carried out to create an overview of the participants' background characteristics.

\section{Primary Analyses}

Linear mixed model analyses were performed on site level to examine the relation between the NVR-MID training and aggressive incidents over time. To test whether NVR-MID was related to a change in aggressive incidents over time, the main effect of the fixed factor time (within-subject: T0-T6) was studied. Residential setting (between-subject: Site 1, Site 2 , Site 3) was added as a fixed variable to the analyses, so that differences between the residential youth care settings could be accounted for. The interaction between time and residential setting was studied to test whether the relation between NVR-MID and the change in aggressive incidents over time was different for the three residential youth care settings. There were no missing data as the design used mean scores.

\section{Post-hoc Analyses}

Results were further explored with post-hoc analyses. Significant main effects were explored with pairwise-comparison tests with a Bonferonni correction. Significant interactions were further explored with one-factor ANOVAs.

\section{Effect Size}

To understand the possible differences between before and after NVR-MID training, first a paired samples $t$-test was performed, and next, the corresponding Cohen's $d$ and its effect size $r$ were calculated.

As we wanted to understand whether the potential change of aggressive incidents could be attributed to the implementation of NVR-MID specifically, we calculated the score of implementation fidelity (IF) with the RUBI-NL and compared the scores before, during and after the NVR-MID training with conducting a one-way between group ANOVA. 
Table 5 Number of mean aggressive incidents and its corresponding standard deviations (SD) calculated per measurement-point for the whole sample (mean total) and each residential site separately

\begin{tabular}{llllllll}
\hline & T0 & T1 & T2 & T3 & T4 & T5 & T6 \\
\hline Site 1 & $42.6(32.9)$ & $37.8(25.7)$ & $27.1(14.9)$ & $37.5(27.8)$ & $24.5(15.4)$ & $24(12.3)$ & $30.5(15.4)$ \\
Site 2 & $21.5(12.6)$ & $18.4(5.4)$ & $10.2(7.2)$ & $13.4(9.0)$ & $11.3(8.9)$ & $13.6(8.6)$ & $5.8(3.3)$ \\
Site 3 & $25.2(16.9)$ & $9.7(6.2)$ & $12.1(8.9)$ & $10.6(7.9)$ & $11.8(3.9)$ & $17.5(6.5)$ & $1.9(1.3)$ \\
Mean total & $25.4(18.4)$ & $16.7(12.8)$ & $12.8(10.2)$ & $14.7(14.2)$ & $12.9(9.0)$ & $16.4(8.8)$ & $6.7(10.1)$ \\
& Before* & & & During* & & After* & \\
Site 1 & 40.2 & & & 29.7 & & 27.2 & \\
Site 2 & 19.9 & & & 11.6 & & 9.7 & \\
Site 3 & 27.2 & & & 9.7 & & 9.7 & \\
\hline
\end{tabular}

*Measurements are averaged as follows: Before NVR-MID=T0, T1; During NVR-MID=T2, T3, T4; After NVR-MID = T5, T6

\section{Exclusion Criterion}

We did not exclude participants with IQ scores below $50(\mathrm{~N}=11)$ and above $85(\mathrm{~N}=3)$ beforehand. We argued that ecological validity would be enhanced if we proceeded from the real scenario on the wards, where different juveniles with a broader range of IQ scores were admitted. Also in our study we worked with mean scores of aggressive incidents, rather than individual scores.

\section{Results}

\section{Descriptive Analyses}

To test whether the 3 sites varied in terms of age, IQ and gender of the participants, three one-way between group ANOVAs were conducted. There was a significant difference in terms of age between the sites $(F 2,125)=0.138, p>0.01$. Post hoc comparison using LSD indicated that mean age of site $1(M=24.92, S D=10.4)$ was significantly higher compared to site $2(M=16.15, S D=4.1)$ and site $3(M=15.25, S D=1.8)$. Site 2 and 3 were not significantly different from each other. In terms of IQ there was a significant difference between the sites $(F 2,62)=17.69, p>0.01$. Post hoc comparison using LSD indicated that mean IQ of site $1(M=49.14, S D=5.1)$ was significantly lower compared to site $2(M=61.52$, $S D=12.2)$ and site $3(M=76.86, S D=7.3)$. IQ at site 2 was significantly lower compared to IQ at site 3 . The sites did not differ significantly in terms of gender $(F(2,125)=0.13$, $p=0.87)$ or problem behavior $(F(2,58)=0.17, p=0.83)$ of the participants.

\section{Preliminary Analyses}

The total amount of aggressive incidents was calculated per unit per month. In order to correspond with the seven measurement points used in this study (T0-T6), we averaged the three-months-range of aggressive incidents corresponding with its measurement point. We did so for the whole sample and each site separately. The seven measurement points were translated into three time points, related to the NVR-MID training: Before (T0, T1), during 
(T2, T3. T4) and after (T5, T6) NVR-MID training (Table 5). For full clarity we carried out all analyses with these three time points only.

\section{Hypothesis Testing}

There turned out to be a significant main effect of the factor time on aggressive incidents $(F(6,762.97)=54.73, p>0.01)$. The number of aggressive incidents changed significantly over time.

\section{Accounting for Residential Setting}

To fully answer the research question whether the NVR-MID training was related to a change in aggressive incidents over time, the factor site was added as a covariate to the linear mixed models' analyses. This was done so that possible differences between the 3 sites regarding aggressive incidents in general (main effects) and how aggressive incidents changed over time (interaction effects) could be accounted for. There were no significant main effects of site on aggressive incidents. Next, the interaction effect between time and site was studied. There turned out to be significant interactions between site and time on aggressive incidents $(F(12,762.97)=12.72, p>0.01)$. The differences between the three residential settings regarding the change in aggressive incidents over time was examined with post-hoc one-factor ANOVAs. Three one-factor ANOVAs were conducted with respectively aggressive incidents before (T0, T1), during (T2, T3, T4) and after (T5, T6) NVR-MID training as dependent variable. Results showed that there was a significant main effect of residential setting before NVR-MID training $(F(2,112)=15.17, p<0.001)$. Posthoc pairwise comparisons with a Bonferroni correction revealed that at site $1(M=40.2$, $S D=29.3)$ the number of aggressive incidents was significantly higher compared to site $2(M=19.9, S D=8.3)$ and site $3(M=17.4, S D=10.5)$. There was also a significant main effect of residential setting during NVR-MID training $(F(2,112)=21.7, p<0.001)$. Again, a post-hoc pairwise comparisons with a Bonferroni correction revealed that at site $1(M=29.7, S D=19.3$ the number of aggressive incidents was significantly higher compared to site $2(M=11.6, S D=7.4)$ and site $3(M=11.5, S D=6.3)$. Finally, there was also a significant main effect of residential setting after NVR-MID training $(F(2,112)=41,9$, $p<0.001)$. The post-hoc pairwise comparisons with a Bonferroni correction revealed that at site $1(M=27.2, S D=13.9)$ the number of aggressive incidents was significantly higher compared to site $2(M=9.7, S D=5.6)$ and site $3(M=9.7, S D=3.3)$. Hence, the significant interaction between time and site in the primary analysis can probably be best explained by the relatively high number of aggressive incidents before, during and after training in NVR-MID at site 1 (see also Fig. 1).

\section{Effect Size}

In order to fully understand whether the significant changes in aggressive incidents before versus after NVR-MID training were meaningful, the effect size was calculated. A paired samples $t$-test was conducted to compare aggressive incidents before and after NVRMID training. There was a significant difference in aggressive incidents before $(M=21.1$, $\mathrm{SD}=14.5)$ and after $(\mathrm{M}=11.6, \mathrm{SD}=8.2)$ NVR-MID training; $t(112)=9.9, p<0.001$; $d=0.80$. The effect size for this analysis $(d=0.80)$ can be interpreted as a large effect (Rice and Harris 2005), see Table 6. 


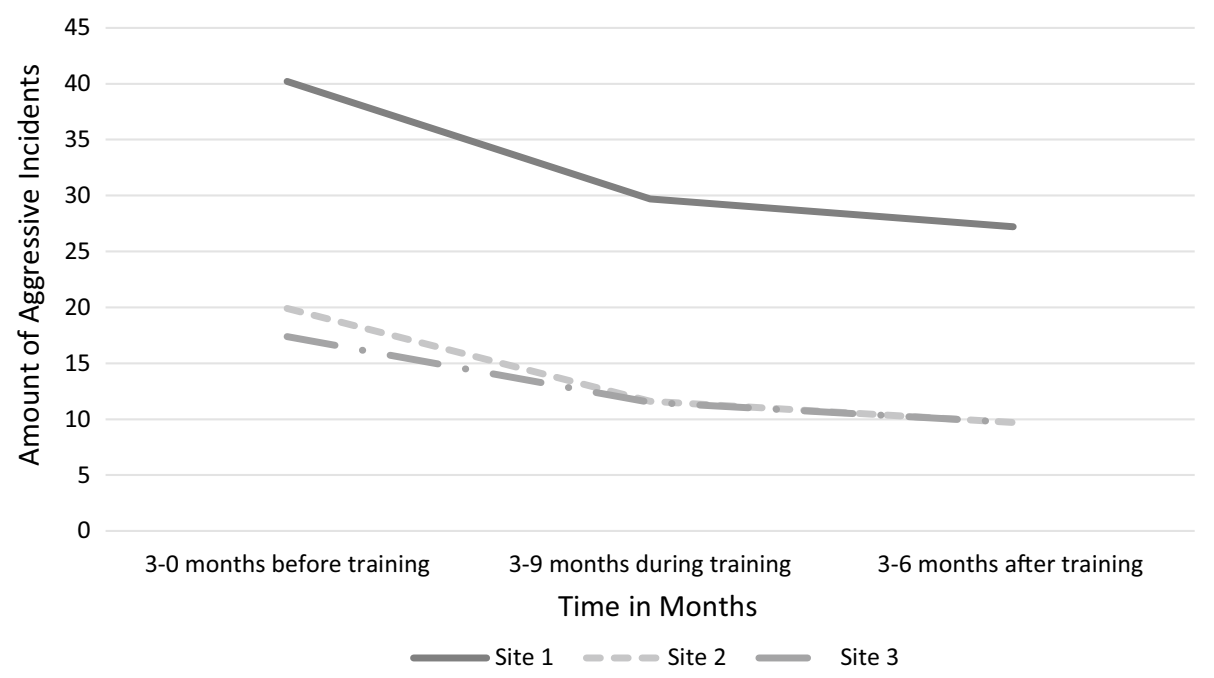

Fig. 1 Aggressive incidents before, during and after training in NVR-MID at the three residential settings

\section{Implementation Fidelity}

There was a significant difference in terms of RUBI-NL scores between the time points before, during and after NVR-MID training $(F 2,138)=7.08, p=0.001$. Post hoc comparison using LSD indicated that mean scores on RUBI-NL before NVR-MID training $(\mathrm{M}=3.48, \mathrm{SD}=0.42)$ were significantly lower compared to after NVR-MID training $(M=3.91, S D=0.45)$. The RUBI-NL scores between before and during $(M=3.55$, $\mathrm{SD}=0.46$ ) or during and after were not significantly different from each other.

\section{Discussion}

This study examined the relationship between the Non-Violent Resistance (NVR) methodology for juveniles with a mild intellectual disability (MID) and comorbid behavioral problems and a possible change in aggressive incidents over time in three residential youth care settings in the Netherlands. Results showed that aggressive incidents significantly decreased during the whole research period, namely before, during and after the NVRMID training. This supports the hypothesis that NVR-MID in residential youth care settings would, over time, be associated with a decrease in aggressive incidents. This decrease in aggressive incidents was seen in all three institutions, yet there were substantial differences between residential settings in terms of age and IQ of the residents. However, these differences between the participants seemed not to have influenced the results. Regardless of the age or IQ of the residents, aggressive incidents decreased after staff had been trained in NVR-MID. This suggests that NVR-MID seems to be successful in diminishing aggressive incidents in residential settings for a broad range of ages and IQ scores of the admitted residents. This is in line with the current study's hypothesis and supports also the earlier finding of a decrease in aggressive incidents of the regular NVR method (thus, not adapted for MID) in an inpatient unit for adolescents (Goddard et al. 2009). Furthermore, research 


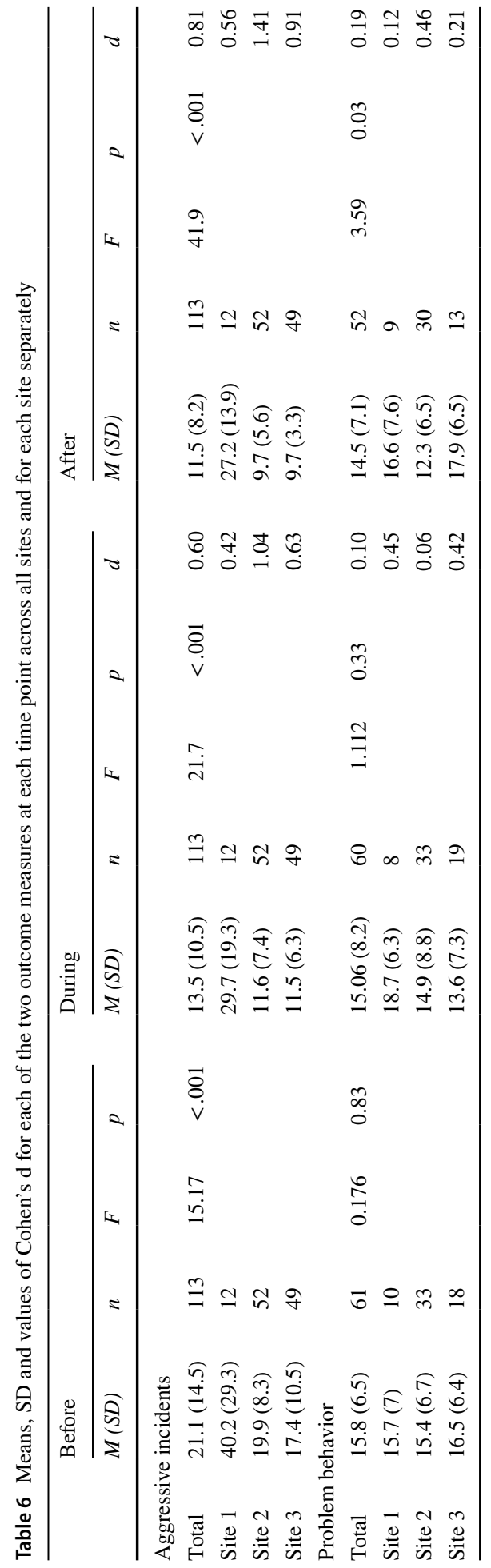


had shown that children's negative behavior decreased as reported by their parents (Weinblatt and Omer 2008) and externalizing behavior decreased among foster children (Van Holen et al. 2016) after the (foster) parents received NVR training. As mentioned in the introduction, aggressive incidents in residential settings for the normal population (thus not MID specific) did not change after implementation of NVR (van Gink et al. 2018a, b). This study is the first to show that the decrease in aggressive incidents applies also to the residential version of NVR for juveniles with MID. Interestingly, the aggressive incidents declined already in the second pre-measurement, thus before the actual NVR-MID training had taken place. That means that this specific decline could not be the result of the NVR-MID intervention directly, because staff had not been trained at that moment. Yet, it is imaginable that staff had already anticipated the training and the prospect of change. This may have been enough to reveal a change in behavior and aggressive incidents. This phenomenon is seen more often in scientific research and is called pre-intervention decrease (van der Leeden et al. 2011). But even if initial decline was not linked to NVRMID directly, aggressive incidents remained to decline in all three institutions throughout the training period and beyond. That leads to the conclusion that after NVR-MID training aggressive incidents decline and the benefits of the NVR-MID training remain after the training has been completed.

We found a significant interaction effect between aggressive incidents and site over time. When comparing the three sites it appeals that aggressive incidents at site 1 are more than twice as high compared to the other 2 sites, at baseline. Interestingly, when comparing before and after NVR-MID training, aggressive incidents declined to a similar the number in all three institutions. That means, that even though aggressive incidents may be high at baseline, NVR-MID seems to be effective in diminishing aggressive incidents either way, which enhances the usability of this method for a broader range of target groups. A possible explanation for the relatively high number of aggressive incidents at site 1 could be the relatively high(er) age and low(er) IQ at site 1 compared to the other two sites. Residents with a lower IQ and higher age are often admitted to an institution for a long period of time or even permanently, due to the difficulties of their close environment (family, friends) to take care of them. These findings are supported by research also. Tillaart et al. (2018) suggests that the length of stay in an institution may be related to the number of aggressive incidents, hence the longer the stay, the greater the number of incidents.

Although the current study's results contribute to the scarce literature on NVR-MID in residential youth care, it has some limitations. First, mild intellectual disability is defined as an IQ score between 50 and 85. Mean IQ at site 1 was $49.14(\mathrm{SD}=5.14)$, which means that the sample included participants which did not fulfil the definition of MID strictly but would rather be defined as having a moderate intellectual disability. We chose not to exclude these participants, based only on their lower IQ score. This resulted in the fact that we kept participants in our sample with an IQ belonging to a moderate rather than a mild intellectual disability. The reason for including these participants was the consideration that in practice there are different clients per ward, not always strictly separated based on their IQ scores. Even at the site with lower IQs than 50, aggressive incidents declined after NVR-MID training, which leads to the conclusion that not only juveniles with MID benefit from NVR-MID, but also juveniles with IQs around 50 and below. This conclusion enhances the generalizability of NVR-MID. Future research could focus on different groups of intellectual functioning around and below 50, to get more insight in this target group.

Further, the number of reported aggressive incidents could be an underestimation of the actual number of incidents occurring in the residential settings as seen in previous 
studies (Ros et al. 2013; Tillaart et al. 2018). When we assume, that the actual number of aggressive incidents would possibly be higher per time-point, the decrease we find would possibly still be visible. This means that even if there has been an underestimation of aggressive incidents in our study, the conclusion that NVR-MID decreases aggressive incidents would still be the same.

The reports of aggressive incidents were coded by researchers not blind to the stages of the implementation of NVR-MID. In order to circumvent possible bias, the researchers coded the aggressive incidents independently from one another and compared their results. This procedure should assure the correct, unbiased interpretation of the results.

Despite its limitations, the current study has a few important strengths that are relevant to highlight. First, this is, to our knowledge, the first study researching the effect of NVR-MID in the residential setting. To date, there exists no research on the application of NVR-MID in residential youth care, even if we know that an adequate approach to this target group is mandatory (de Wit et al. 2011; Didden and Moonen 2007, 2009). Consequently, effective treatment methods for juveniles with MID should be given more significance.

Further, this study has a solid methodology, as it is a longitudinal approach with seven measurement points spread over a time frame of 20 months. Generalizability is enhanced as three different institutions participated in a quasi-experimental stepped wedge design. The NVR-MID training was introduced in phases (Site 1: Aug.' 16-Apr. '18; Site 2: Nov. '16-Jul. '18; Site 3: Feb. '17-Oct. '18). The stepped wedge design allows the sites to function as their own control group (before versus after NVR-MID training). In addition, possible influences through seasonal factors (such as stress and excitement in the Christmas period or during holidays) could be detected easily as they would be prominent at all sites and influence the results in the same way.

Lastly, reports of aggressive incidents were used from participants of the whole unit per site, not only from the participants that were enrolled in this study. That adds to the generalizability of the results.

To conclude, the current study showed a significant relationship between the training in the residential NVR-MID and a decrease in aggressive incidents in residential youth care over time. The decrease was seen in all three sites, despite juveniles' gender, age and IQ. Even for juveniles with IQs around and below 50 (moderate intellectual disability), aggressive incidents declined. As aggression is high in residential settings for juveniles with MID, it was very important to address this matter. As this was the first study to research this specific topic it is warranted to conduct robust randomized trials in order to validate our findings. In the future, this could mean that NVR-MID could be implemented into more residential settings which struggle with high amounts of aggressive incidents. Less aggressive incidents are associated with a better treatment environment for the admitted juveniles and a better working environment for staff, which should be the ultimate goal of treatment for juveniles in residential youth care settings.

Acknowledgements The authors would like to thank all staff members and admitted juveniles of the three child and adolescent residential settings that were willing to provide information for this paper.

\section{Funding}

\section{Compliance with Ethical Standards}

Conflict of interest K.M. Visser declares she has no conflict of interest. L.C.M. Jansen declares that she has no conflict of interest. A. Popma declares he has no conflict of interest. R.R.J.M. Vermeiren declares he has 
no conflict of interest. M.C. Kasius declares she has no conflict of interest.

Ethical Approval All procedures performed in studies involving human participants were in accordance with the ethical standards of the institutional and/or national research committee (include name of committee + reference number) and with the 1964 Helsinki declaration and its later amendments or comparable ethical standards.

Informed Consent Informed consent was obtained from all individual participants included in the study.

Open Access This article is licensed under a Creative Commons Attribution 4.0 International License, which permits use, sharing, adaptation, distribution and reproduction in any medium or format, as long as you give appropriate credit to the original author(s) and the source, provide a link to the Creative Commons licence, and indicate if changes were made. The images or other third party material in this article are included in the article's Creative Commons licence, unless indicated otherwise in a credit line to the material. If material is not included in the article's Creative Commons licence and your intended use is not permitted by statutory regulation or exceeds the permitted use, you will need to obtain permission directly from the copyright holder. To view a copy of this licence, visit http://creativecommons.org/licenses/by/4.0/.

\section{References}

Achenbach, T., McConaughy, S., Ivanova, M., \& Rescorla, L. (2011). Manual for the ASEBA brief problem monitor (BPM) (pp. 1-33). Burlington, VT: ASEBA.

Achenbach, T. M. (1991). Integrative guide for the 1991 CBCL/4-18, YSR, and TRF profiles: Department of psychiatry. Burlington: University of vermont.

American Psychiatric Association. (2000). Diagnostic and statistical manual of mental disorders (4th ed., text rev.). Washington, DC.

Brown, C. A., \& Lilford, R. J. (2006). The stepped wedge trial design: A systematic review. BMC medical research methodology, 6(1), 54.

Campbell, D. T., \& Cook, T. D. (1979). Quasi-experimentation: Design and analysis issues for field settings. Rand McNally College Publishing Company Chicago.

Cowley, A., Newton, J., Sturmey, P., Bouras, N., \& Holt, G. (2005). Psychiatric inpatient admissions of adults with intellectual disabilities: Predictive factors. American Journal on Mental Retardation, 110(3), 216-225.

Crick, N. R., \& Dodge, K. A. (1994). A review and reformulation of social information-processing mechanisms in children's social adjustment. Psychological bulletin, 115(1), 74.

Crocker, A. G., Mercier, C., Lachapelle, Y., Brunet, A., Morin, D., \& Roy, M. E. (2006). Prevalence and types of aggressive behaviour among adults with intellectual disabilities. Journal of Intellectual Disability Research, 50(9), 652-661.

Crotty, G., Doody, O., \& Lyons, R. (2014). Identifying the prevalence of aggressive behaviour reported by registered intellectual disability nurses in residential intellectual disability services: An Irish perspective. Advances in Mental Health and Intellectual Disabilities, 8(3), 174-187.

de Wit, M., Moonen, X. M. H., \& Douma, J. C. H. (2011). Richtlijn effectieve interventies LVB: Aanbevelingen voor het ontwikkelen, aanpassen en uitvoeren van gedragsveranderende interventies voor jeugdigen met een licht verstandelijke beperking: Landelijk Kenniscentrum LVG.

Didden, \& Moonen. (2007). Met het oog op behandeling: Effectieve behandeling van gedragsstoornissen bij mensen met een licht verstandelijke beperking.

Didden, \& Moonen. (2009). Met het oog op behandeling 2 congres: Effectieve behandeling van gedragsstoornissen bij mensen met een lichte verstandelijke beperking.

Edwards, P., \& Miltenberger, R. (1991). Burnout among staff members at community residential facilities for persons with mental retardation. Mental Retardation, 29(3), 125-128.

Embregts, P., Didden, R., Huitink, C., \& Schreuder, N. (2009). Contextual variables affecting aggressive behaviour in individuals with mild to borderline intellectual disabilities who live in a residential facility. Journal of Intellectual Disability Research, 53(3), 255-264.

Emerson, E., Kiernan, C., Alborz, A., Reeves, D., Mason, H., Swarbrick, R., et al. (2001). The prevalence of challenging behaviors: A total population study. Research in Developmental Disabilities, 22(1), 77-93. 
Fontaine, R. G., \& Dodge, K. A. (2009). Social information processing and aggressive behavior: A transactional perspective. Washington: American Psychological Association.

Gardner, W. I., \& Moffatt, C. W. (1990). Aggressive behaviour: Definition, assessment, treatment. International Review of Psychiatry, 2(1), 91-100.

Goddard, N., Van Gink, K., Van der Stegen, B., Van Driel, J., \& Cohen, A. (2009). Smeed het ijzer als het koud is. Non-Violent Resistance op een acuut psychiatrische afdeling voor adolescenten. Maandblad Geestelijke Volksgezondheid, 64, 531-539.

Haspels, M., Visser, K. M., Van Gink, K., \& Van der Stegen, B. (2017). Geweldloos verzet in (semi-)residentiële setting de Bascule.

Helm, V. d., \& Stams. (2012). Conflict and coping by clients and group workers in secure residential facilities. Progression in forensic psychiatry: About boundaries, 553-564.

Hunter, M., \& Carmel, H. (1992). The cost of staff injuries from inpatient violence. Psychiatric Services, 43(6), 586-588.

Jackson, D., Clare, J., \& Mannix, J. (2002). Who would want to be a nurse? Violence in the workplace: A factor in recruitment and retention. Journal of nursing management, 10(1), 13-20.

James, S. (2011). What works in group care?: A structured review of treatment models for group homes and residential care. Children and youth services review, 33(2), 308-321.

Kazdin, A. E. (2005). Treatment outcomes, common factors, and continued neglect of mechanisms of change. Clinical Psychology: Science and Practice, 12(2), 184-188.

Legerstee, J. S., van der Reijden-Lakeman, I. A., Lechner-van der Noort, M. G., \& Ferdinand, R. F. (2004). Bruikbaarheid verkorte versie WISC-RN in de kinderpsychiatrie. Kind en adolescent, 25(4), 178.

Lipsey, M. W. (2009). The primary factors that characterize effective interventions with juvenile offenders: A meta-analytic overview. Victims and offenders, 4(2), 124-147.

Liu, J. (2004). Childhood externalizing behavior: Theory and implications. Journal of Child and Adolescent Psychiatric Nursing, 17(3), 93-103.

Livingston, J. D., Verdun-Jones, S., Brink, J., Lussier, P., \& Nicholls, T. (2010). A narrative review of the effectiveness of aggression management training programs for psychiatric hospital staff. Journal of Forensic Nursing, 6(1), 15-28.

Natta, M. B., Holmbeck, G. N., Kupst, M. J., Pines, R. J., \& Schulman, J. L. (1990). Sequences of staff-child interactions on a psychiatric inpatient unit. Journal of abnormal child psychology, 18(1), 1-14.

Omer, H. (2004). Non-violent resistance. Cambridge: Cambridge University Press.

Omer, H., \& Lebowitz, E. R. (2016). Nonviolent resistance: Helping caregivers reduce problematic behaviors in children and adolescents. Journal of marital and family therapy, 42(4), 688-700.

Parhar, K. K., Wormith, J. S., Derkzen, D. M., \& Beauregard, A. M. (2008). Offender coercion in treatment: A meta-analysis of effectiveness. Criminal Justice and Behavior, 35(9), 1109-1135.

Patterson, G., \& Forgatch, M. (1985). Therapist behavior as a determinant for client noncompliance: A paradox for the behavior modifier. Journal of consulting and clinical psychology, 53(6), 846-851.

Pfeffer, C. R., Solomon, G., Plutchik, R., Mizruchi, M. S., \& Weiner, A. (1985). Variables that predict assaultiveness in child psychiatric inpatients. Journal of the American Academy of Child Psychiatry, 24(6), 775-780.

Rice, M. E., \& Harris, G. T. (2005). Comparing effect sizes in follow-up studies: ROC Area, Cohen's d, and r. Law and human behavior, 29(5), 615-620.

Ros, N., Van der Helm, P., Wissink, I., Stams, G.-J., \& Schaftenaar, P. (2013). Institutional climate and aggression in a secure psychiatric setting. The Journal of Forensic Psychiatry and Psychology, 24(6), 713-727.

Sameroff, A. (2009). The transactional model. Washington: American Psychological Association.

Sanders, M. R., Mazzucchelli, T. G., \& Studman, L. J. (2004). Stepping stones triple P: The theoretical basis and development of an evidence-based positive parenting program for families with a child who has a disability. Journal of Intellectual and Developmental Disability, 29(3), 265-283.

Schudrich, W. (2012). Implementing a modified version of parent management training (PMT) with an intellectually disabled client in a special education setting. Journal of evidence-based social work, 9(5), 421-432.

Sukhodolsky, D. G., Cardona, L., \& Martin, A. (2005). Characterizing aggressive and noncompliant behaviors in a children's psychiatric inpatient setting. Child Psychiatry and Human Development, 36(2), $177-193$.

Tenneij, N., \& Koot, H. M. (2008). Incidence, types and characteristics of aggressive behaviour in treatment facilities for adults with mild intellectual disability and severe challenging behaviour. Journal of Intellectual Disability Research, 52(2), 114-124. 
Tillaart, J Vd, Eltink, E., Stams, G. J., Helm, P Vd, \& Wissink, I. (2018). Aggressive incidents in residential youth care. International Journal of Offender Therapy and Comparative Criminology. https://doi. org/10.1177/0306624x18758898.

van der Helm, P., Klapwijk, M., Stams, G., \& van der Laan, P. (2009). 'What works' for juvenile prisoners: the role of group climate in a youth prison. Journal of Children's Services, 4(2), 36-48.

van der Leeden, A. J., van Widenfelt, B. M., van der Leeden, R., Liber, J. M., Utens, E. M., \& Treffers, P. D. (2011). Stepped care cognitive behavioural therapy for children with anxiety disorders: A new treatment approach. Behavioural and Cognitive Psychotherapy, 39(1), 55-75.

van Gink, K., Vermeiren, R., Goddard, N., van Domburgh, L., van der Stegen, B., Twisk, J., et al. (2018a). The influence of non-violent resistance on work climate, living group climate and aggression in child and adolescent residential care. Children and youth services review, 94, 456-465.

van Gink, K., Visser, K., Popma, A., Vermeiren, R., van Domburgh, L., van der Stegen, B., et al. (2018b). Implementing non-violent resistance, a method to cope with aggression in child and adolescent residential care: Exploration of staff members experiences. Archives of Psychiatric Nursing, 32(3), 353-359.

Van Holen, F., Vanderfaeillie, J., \& Omer, H. (2016). Adaptation and evaluation of a nonviolent resistance intervention for foster parents: A progress report. Journal of marital and family therapy, 42(2), 256-271.

Van Nieuwenhuijzen, M., Bijman, E., Lamberix, I., Wijnroks, L., De Castro, B. O., Vermeer, A., et al. (2005). Do children do what they say? Responses to hypothetical and real-life social problems in children with mild intellectual disabilities and behaviour problems. Journal of Intellectual Disability Research, 49(6), 419-433.

Van Nieuwenhuijzen, M., De Castro, B. O., Van der Valk, I., Wijnroks, L., Vermeer, A., \& Matthys, W. (2006). Do social information-processing models explain aggressive behaviour by children with mild intellectual disabilities in residential care? Journal of Intellectual Disability Research, 50(11), 801-812.

Van Nieuwenhuijzen, M., Orobio de Castro, B., Van Aken, M., \& Matthys, W. (2009). Impulse control and aggressive response generation as predictors of aggressive behaviour in children with mild intellectual disabilities and borderline intelligence. Journal of Intellectual Disability Research, 53(3), 233-242.

Visser, K. M., van Gink, K., Thissen, F., Visser, T. A., Rimehaug, T., Jansen, L. C. M., et al. (2019). Development and preliminary evaluation of the reaction to unacceptable behavior inventory: A questionnaire to measure progress in implementation of non-violent resistance. Child and Youth Care Forum. https:// doi.org/10.1007/s10566-019-09517-5.

Wechsler, D. (1949). Wechsler intelligence scale for children.

Weinblatt, U., \& Omer, H. (2008). Nonviolent resistance: a treatment for parents of children with acute behavior problems. Journal of marital and family therapy, 34(1), 75-92.

Wielemaker, J. (2009). Langdurig klinisch behandeld in de kinder-en jeugdpsychiatrie; Een follow-up onderzoek na 5 tot 25 jaar.

Zeller, A., Dassen, T., Kok, G., Needham, I., \& Halfens, R. J. (2012). Factors associated with resident aggression toward caregivers in nursing homes. Journal of nursing scholarship, 44(3), 249-257.

Zoon, M. (2013). Kenmerken en oorzaken van een licht verstandelijke beperking. Utrecht: NJi.

Publisher's Note Springer Nature remains neutral with regard to jurisdictional claims in published maps and institutional affiliations.

\section{Affiliations}

\section{K. M. Visser ${ }^{1,2} \cdot$ L. M. C. Jansen ${ }^{1} \cdot$ A. Popma ${ }^{1,4} \cdot$ R. R. J. M. Vermeiren ${ }^{3} \cdot$ M. C. Kasius ${ }^{2}$}

1 Department of Child and Adolescent Psychiatry, VU University Medical Center, Meibergdreef 5 , 1105 AZ Amsterdam ZO, The Netherlands

2 Parnassia Group, Youz, De Banjaard, The Hague, The Netherlands

3 Department of Child and Adolescent Psychiatry, Leiden University Medical Center, Oegstgeest, The Netherlands

4 Department of Criminal Law and Criminology, Leiden University, Leiden, The Netherlands 